\title{
Transovarial passage and transmission of LSDV by Amblyomma hebraeum, Rhipicephalus appendiculatus and Rhipicephalus decoloratus
}

Jimmy C. Lubinga ${ }^{1,3}$, Eeva S.M. Tuppurainen ${ }^{2}$, Jacobus A. W. Coetzer ${ }^{1}$, Wilhelm H. Stoltsz ${ }^{1}$, Estelle H. Venter ${ }^{1}$

${ }^{1}$ University of Pretoria, Onderstepoort, Pretoria, South Africa (Jimmy C. Lubinga, Jacobus A.W.Coetzer, Wilhelm H. Stoltsz and Estelle H. Venter); ${ }^{2}$ The Pirbright Institute, Pirbright, Surrey, UK (Eeva S.M. Tuppurainen); ${ }^{3}$ Department of Veterinary and Tsetse Control Services, Provincial Veterinary Office, Kasama, Zambia (Jimmy C. Lubinga)

Mailing address: Department of Veterinary Tropical Diseases, Faculty of Veterinary Science University of Pretoria, Private bag X04, Onderstepoort, 0110, Pretoria, South Africa. Phone +27 012 529 8382, Fax+27012529 8312. e-mail jimlubinga@yahoo.com

\section{Abstract}

Lumpy skin disease (LSD), an acute, sub-acute or innapparent disease of cattle, is caused by lumpy skin disease virus (LSDV), a member of the genus Capripoxvirus in the family Poxviridae. Lumpy skin disease is characterised by high fever, formation of circumscribed skin lesions and ulcerative lesions on the mucous membranes of the mouth, respiratory and digestive tracts. It is an economically important disease due to the permanent damage to hides, the reduction in productivity and trade restrictions imposed on affected areas.

Transmission has been associated with blood-feeding insects such as stable flies (Stomoxysis calcitrans) and mosquitoes (Aedes aegypti). Mechanical (intrastadial) and transstadial transmission by Amblyomma hebraeum and Rhipicephalus appendiculatus as well as transovarial transmission by Rhipicephalus decoloratus have been reported. 
In this study transovarial passage of LSDV to larvae and subsequent transmission to recipient animals were demonstrated. The finding of transovarial passage of LSDV in female ticks shows the potential for A. hebraeum, R. appendiculatus and $R$. decoloratus to be reservoir hosts for LSDV.

Key words: Transovarial transmission, Amblyomma hebraeum, Rhipicephalus appendiculatus, Rhipicephalus decoloratus, tick eggs, larvae, lumpy skin disease virus

\section{Introduction}

Lumpy skin disease virus (LSDV) is a member of the genus Capripoxvirus in the family Poxviridae (King et al. 2011). It causes lumpy skin disease (LSD) which affects all age groups and breeds of cattle. Lumpy skin disease is characterised by high fever, multiple circumscribed firm skin nodules, enlargement of superficial lymph nodes, salivation, lachrimation, rhinitis and keratitis. The disease is of economic importance due to the severe damage to hides, reduced milk and meat production, temporary infertility and trade losses due to movement restrictions placed on cattle from affected areas. (Davies 1981, Kumar 2011, Weiss 1968).

Haematophagous insects have mostly been associated with the transmission of LSDV. In Kenya (1957), the LSD outbreak was associated with a high prevelance of Aedes natronius and Culex mirificens mosquitoes (Burdin 1959) while the outbreak in Israel (1989) was attributed to Stomoxys calcitrans carried by wind from Ismailiya to Egypt (Yeruham et al. 1995). The demonstration of mechanical transmission of LSDV by Aedes aegypti in the laboratory suggests the ability of mosquitoes and other biting insects to transmit LSDV under natural conditions (Chihota et al. 2001). Ticks have recently been implicated in the 
transmission of LSDV (Tuppurainen et al. 2011, Tuppurainen and Oura 2012). Mechanical transmission of the virus by Rhipicephalus appendiculatus has been demonstrated (Tuppurainen et al. 2013a), while mechanical and transstadial transmission by Amblyomma hebraeum have been demonstrated by Lubinga et al (submitted). Lumpy skin disease has also been detected in saliva samples collected from A. hebraeum and $R$. appendiculatus adults that fed on infected cattle as nymphs or as adults (Lubinga et al. 2013). Transovarial transmission of LSDV by R. decoloratus larvae to cattle was reported by Tuppurainen and co-workers (2013b).

In this study the passage of LSDV from infected female ticks through the eggs to the next generation larvae is demonstrated in A. hebraeum, $R$. appendiculatus and $R$. decoloratus. Transmission to recipient animals by A. hebraeum and R. appendiculatus larvae was also shown

\section{Materials and methods}

Eight LSDV sero-negative Bonsmara cattle were used in the study; six were experimentally infected with LSDV virus and acted as donor animals (Tuppurainen et al. 2013a). The donor animals were paired and each pair hosted adult A. hebraeum, R. appendiculatus and $R$. decoloratus, respectively. The other two animals were used as recipient animals to demonstrate transmission by $A$. hebraeum and $R$. appendiculatus larvae respectively. The recipient animals were kept in separate rooms in insect-free stables at the University of Pretoria’s Bioscience Research Centre (UPBRC). Donor cattle were infected in October 2010 and were removed from the animal facilities by the end of November 2010. The facilities were then cleaned and disinfected according to the standard operating procedures of UPBRC. The recipient animals were brought into the facilities in the beginning of February 
2011 and during the time that the recipient cattle were housed at the insect-free isolation unit where there were no animals infected with LSDV or other capripoxviruses. All the experimental procedures for the animals were approved by the Animal Use and Care Committee (AUCC) of the University of Pretoria (UP), South Africa.

A South African LSDV field isolate (248/93), was used in the study to artificially infect donor animals. It was propagated on primary bovine dermis cells for five to six passages at the Virology Section of the Department of Veterinary Tropical Diseases (DVTD), UP. The titre of the virus was $5.95 \log \mathrm{TCID}_{50} / \mathrm{ml}$.

The donor animals were infected with $3.5 \mathrm{ml}$ of the prepared LSDV inoculum (Tuppurainen et al. 2013a).

Unfed A. hebraeum and $R$. appendiculatus adult ticks and $R$. decoloratus larvae were reared at the Agricultural Research Council's Onderstepoort Veterinary Institute (ARC-OVI). These ticks were exposed to LSDV infection by feeding them on two infected donor animals each for $A$. hebraeum, $R$. appendiculatus and $R$. decoloratus during the viraemic stage as follows: Seventy five (F1 adult) A. hebraeum males were placed in two cotton cloth bags attached with Genkem contact adhesive glue on the body sides of donor animals on Day 4 post infection (pi). Twenty five females were added to the bags containing the males four days later as described by Lubinga et al (2013). Engorged females were collected after feeding to repletion for 6 to 8 days. They were incubated in an acaridarium at $25^{\circ} \mathrm{C}$ and $85 \%$ relative humidity (RH) to oviposit and for the eggs to hatch. After hatching, the larvae were further incubated for approximately one month, to allow for their maturation to complete. To test for transovarial passage of LSDV to larvae, four pooled samples from five females containing approximately 300 larvae each were collected and stored at $-80^{\circ} \mathrm{C}$ for testing by real-time polymerse chain reaction (PCR) and virus isolation (VI). To test for transovarial 
transmission, approximately 500 pooled larvae were placed on the ears of recipient animal RA4 in cotton cloth bags, attached at the base of the ears. This was designated Day 0 post attachment (0 dpa).

To infect $R$. appendiculatus, 100 unfed adult ticks were placed in cotton cloth bags attached to the base of the ears of donor animals. Engorged $R$. appendiculatus females were collected after feeding to repletion on Days 6 to 7 (pi.). They were incubated to lay eggs and for the eggs to hatch as for A. hebraeum. Samples of larvae were collected for testing by real-time PCR and VI. Approximately 500 larvae were placed in cotton bags attached to the base of the ears of recipient animal RR2 to test for transovarial transmission by $R$. appendiculatus.

The transovarial transmission of LSDV by $R$. decoloratus was reported by Tuppurainen and co-workers (2013b). In the present study, a sample of the potentially infected larvae were tested for LSDV by real-time PCR and VI to confirm the transovarial passage of LSDV by $R$. decoloratus as described for A. hebraeum larvae.

At the time of tick feeding, the presence of LSDV in donor animals was indicated by clinical signs and confirmed by serum neutralisation test (SNT) and real-time PCR (Lubinga et al. 2013, Tuppurainen et al. 2013a, Tuppurainen et al. 2013b).

Successful transovarial transmission to recipient animals was tested by clinical examination, VI, SNT and real-time PCR. Blood was collected from recipient animals (RA4 and RR2) on 0, 5, 7- 9, 12 - 16, 20 - 22, 27 and 28 (dpa). Blood was collected in EDTA vacutainer tubes for real-time PCR, in heparin tubes for VI and serum for the SNT. Blood samples were stored at $-20^{\circ} \mathrm{C}$ until processed. 
Clinical monitoring of animals

Donor animals were monitored daily from Day 0 - 30 days pi, for rise in body temperature, development or presence of circumscribed skin lesions and enlargement of peripheral lymph nodes. Similarly, recipient animals were observed from Day 0 to Day 30 post attachment (pa) of potentially infected ticks. Depending on the severity of these parameters, the disease was classified as severe, i.e. with high fever (body temperature above $40^{\circ} \mathrm{C}$ ) and skin lesions more than $6 \mathrm{~mm}$ in diameter; mild disease i.e. mild fever $\left(39.1^{\circ} \mathrm{C}\right.$ to $\left.40^{\circ} \mathrm{C}\right)$ and small or transient skin lesions less than $6 \mathrm{~mm}$; no disease or inapparent where no clinical signs were detected. Animals that developed severe clinical signs including eruptive lesions were treated with antibiotics to prevent secondary bacterial infections.

\section{Homogenisation of larvae}

Approximately $1 \mathrm{~g}$ of pooled larvae were washed three times in phosphate buffered saline containing $\mathrm{Ca}^{2+}$ and $\mathrm{Mg}^{2+}\left(\mathrm{PBS}^{+}\right.$) and 0.2\% Gentamycin (Genta 50, Virbac Animal Health, 50 $\mathrm{mg} / \mathrm{ml}$ ) and 0.5\% fungizone (Gibco®fungizone, Life technologies) to reduce other microbial contaminants as well as to rinse off any LSDV adhered to surface of the larvae. The cleaned samples were placed in tubes containing beads and $600 \mu \mathrm{l}$ of Minimum Essential Medium (MEM) with 5\% foetal calf serum, $0.2 \%$ gentamycin and $0.5 \%$ fungizone and cooled at $80^{\circ} \mathrm{C}$ for 5 minutes. The larvae were then homogenised using a Precelly’s 24 Lysis and Homogenizer (Bertin Technologies, France) at 6500 rpm twice for a total of 5 minutes. Of the tick homogenate collected, $200 \mu \mathrm{l}$ was used for DNA extraction and $200 \mu \mathrm{l}$ for VI.

\section{DNA extraction and real time PCR}

Extraction of DNA from cattle blood and tick homogenates was based on the protocol used by Tuppurainen and co-workers (Tuppurainen et al. 2005). Proteins were digested by adding 
2- 4 IU of proteinase K (Roche products, Mannheim, Germany) (10 mg/ml) to samples followed by incubation at $56^{\circ} \mathrm{C}$ for 2 hours (blood) or overnight (tick homogenate).

A real-time PCR, Taqman assay, was used to amplify the extracted DNA (Bowden et al. 2008). An 89 bp region within the Capripoxvirus ORF 74 region that encodes the intracellular mature protein P32 was amplified. Capripoxvirus-specific primers and probes with the following sequences were used: Forward primer-CaPV074F1 5'-AAA ACG GTA TAT GGA ATA GAG TTG GAA-3', Reverse primer- CaPV074R1 5'-AAA TGA AAC CAA TGG ATG GGA TA-3’ and Probe CaPV074P1 5’FAM-TGG CTC ATA GAT TTC CT-MGB/NFQ -3’ (Bowden et al. 2008).

The reaction was performed using a Light Cycler®, 2.0 (Roche products, Mannheim, Germany). The reaction mixture comprised $4 \mu$ l of 10X FastStart DNA Master ${ }^{\text {plus }}$ HybProbe kit (Roche Products), $1 \mu \mathrm{l}(0.1 \mu \mathrm{M})$ each of the primers, $1 \mu \mathrm{l}(0.2 \mu \mathrm{M})$ of hybridization probe, $0.5 \mu \mathrm{l}$ of UDG, $8.5 \mu \mathrm{l}$ of water and $4 \mu \mathrm{l}$ of DNA template (up to $500 \mathrm{ng}$ ). The reaction was run according to the procedures described by Bowden et al. (2008). DNA extracted from LSDV infected cell cultures was used as positive control. Negative controls included a water sample processed through the DNA extraction procedures and a no-DNA template water control.

\section{Serum neutralisation test}

Neutralizing antibodies were measured using a constant-virus/varying-serum neutralising method (Beard et al. 2010) and bovine dermis cells. Negative sera controls were collected from research animals before LSDV inoculation or attachment of ticks. Sera from artificially infected (donor) animals were used as positive sera controls. Titres were determined as the last dilution that gave $50 \%$ neutralization. 
Virus isolation

Virus isolation from blood samples was performed according to previously published methods (Tuppurainen et al. 2005). A similar procedure for VI from tick homogenates was followed. To reduce toxicity to the monolayers, $100 \mu \mathrm{l}$ of tick-homogenate was added to 900 $\mu \mathrm{l}$ of MEM (1/10 dilution) and $300 \mu \mathrm{l}$ of the diluted homogenate was added to the monolayers. Monolayers were observed daily for cytopathic effect (CPE). In the absence of CPE, 2 to 3 blind passages on cell cultures were performed and supernatants were tested by real-time PCR to confirm the presence of LSDV and as the cause of CPE. The VI materials for recipient animals (RA4 and RR2) after the third passage were pooled and concentrated using the PEG kit (BioVision Research Products, Mountain view, USA) and also tested by real-time PCR

\section{Results}

The clinical signs observed in donor animals were reported by Tuppurainen et al, (2013); Tuppurainen et al (2013b); Lubinga et al. (2013). Homogenates of A. hebraeum larvae tested positive for LSDV by real-time PCR with Ct values of 36.7, 37.23 and 39.87. Homogenates of $R$. appendiculatus larvae were all negative by real-time PCR. One homogenate sample for R. decoloratus larvae was positive with a Ct value of 39.75 .

Cytopathic effects were observed in cell cultures for A. hebraeum and $R$. decoloratus larvae while no CPE was observed on cell cultures for R. appendiculatus larvae. Testing by realtime PCR of VI supernatants showed the presence of LSDV in cultures of all 3 species with Ct values between 32.54 and 37.43 (Table 1). 
Table 1. Real-time PCR of tick homogenate and virus isolation supernatants for Amblyomma hebraeum, Rhipicephalus appendiculatus and Rhipicephalus decoloratus larvae

\begin{tabular}{|c|c|c|c|c|}
\hline \multirow[t]{2}{*}{ Tick species } & \multicolumn{2}{|c|}{$\begin{array}{l}\text { Real time PCR (tick } \\
\text { homogenate }\end{array}$} & \multicolumn{2}{|c|}{$\begin{array}{l}\text { Real time PCR (Virus isolation } \\
\text { supernatant) }\end{array}$} \\
\hline & Result & $C_{t}$ value & Result & $C_{t}$ value \\
\hline \multirow[t]{4}{*}{ A. hebraeum } & Positive & 39.87 & Positive & 32.88 \\
\hline & Positive & 36.7 & Positive & 32.54 \\
\hline & Positive & 37.23 & Positive & 35.69 \\
\hline & Negative & $>40$ & Positive & 34.24 \\
\hline \multicolumn{5}{|l|}{ R. appendiculatus } \\
\hline & Negative & - & Positive & 36.59 \\
\hline & Negative & - & Negative & - \\
\hline & Negative & - & positive & 35.91 \\
\hline \multirow[t]{4}{*}{ R. B. decoloratus } & Positive & 39.75 & Positive & 37.43 \\
\hline & Negative & $>40$ & Negative & $>40$ \\
\hline & & - & Negative & $>40$ \\
\hline & & - & Positive & 33.41 \\
\hline
\end{tabular}

Attachment by A. hebraeum larvae on the ears of recipient animals RR2 and RA4 was very high, approaching 100\%. The recipient animal (RA4) representing transovarial transmission by $A$. hebraeum showed no increase in body temperature throughout the study, except on 6 dpa when the temperature rose to $39.4^{\circ} \mathrm{C}$. All other clinical parameters and temperature for RA4 remained normal for the rest of the observation period.

Serum obtained from recipient animal RA4, was negative by SNT throughout the study. The real-time PCR results of blood samples were also negative for LSDV and no CPE was observed from blood samples of RA4. However, the $2^{\text {nd }}$ passage of cell culture media used for VI, tested positive for LSDV real-time PCR on day 14 pi with a Ct value of 37.7.

Recipient animal RR2 used for $R$. appendiculatus larvae showed a slight temperature raise to $39^{\circ} \mathrm{C}$ on Day 6 pi, $39.1^{\circ} \mathrm{C}$ on Day 13 pi and $39.3^{\circ} \mathrm{C}$ on Day 22 pi. No other clinical signs were observed. Viraemia was detected on days 6, 21 and 23 with $C_{t}$ values of 39.24, 36.7 and 38.1, respectively. Cytopathic effects were observed on cell cultures inoculated with heparinised blood on days 8 to 22 pi. Testing of VI material by real-time PCR confirmed 
LSDV with $C_{t}$ values of 39.13 on Day 19; 39.94 on Day 20 and 38.8 on Day 21 pi. The $C_{t}$ values from the pooled and concentrated VI material were 35.85 for RA5 and 28.75 for RR2

\section{Discussion}

The detection of LSDV in larvae of A. hebraeum, R. decoloratus and $R$. appendiculatus indicates transovarial passage of LSDV by these tick species. Washing of the larvae three times helped to reduce possible surface contamination of the larvae by the virus, thereby increasing the confidence that the virus detected passed through the larval tissues.

The $\mathrm{C}_{\mathrm{t}}$ values for real-time PCR of tick homogenates and the VI material were lower for $A$. hebraeum larvae than for $R$. decoloratus and $R$. appendiculatus. It has been shown that during real-time PCR, the lower the $\mathrm{C}_{\mathrm{t}}$ values obtained, the higher the target DNA sequences in the test material (Higuchi et al. 1993). The $C_{t}$ values obtained from testing larval samples suggest that more efficient transovarial passage of LSDV occurred by A. hebraeum than $R$. decoloratus and R. appendiculatus. However, transmission tests in recipient animals showed more efficient transovarial transmission by $R$. decoloratus than $R$. appendiculatus and $A$. hebraeum. The recipient animals (RB2 and RB3) of R. decoloratus larvae showed more evidence of LSDV infection (i.e. skin lesions, oral lesions, salivation), the $C_{t}$ values for realtime PCR of blood were lower and the virus was demonstrated from the skin lesions (Tuppurainen et al. 2013b). Low efficiency of transovarial transmission of viruses by 3-host ticks was reported for Crimean Congo Haemorrhagic Fever (CCHF) by Hyalomma truncatum (Wilson et al. 1991) and tick borne-encephalitis by Ixodes ricinus (Danielova and Holubova 1991). This may explain the apparent low efficiency of transovarial transmission of LSDV A. hebraeum and $R$. appendiculatus observed in this study.

Clinically, recipient animal RA4 (A. hebraeum) did not indicate development of LSD, except for the slight elevation in body temperature on Day 6. Fever is one of the characteristic signs 
for LSD (Coetzer 2004, Weiss 1968) and a transient rise in body temperature of animals is consistent with findings in the other studies involving $R$. appendiculatus (Tuppurainen et al. 2013a) and R. decoloratus (Tuppurainen et al. 2013b), where recipient animals showed a transient raise in temperature between days 4 to 8 of attachment. A similar transient temperature rise was also recorded by Carn and Kitching (1995), when they monitored clinical response to artificial infection with LSDV. However, fever alone is not indicative of LSDV infection, since it is common to most other infectious conditions. The detection of LSDV in blood of RA4 confirms transmission of the virus. Since LSDV was only detected in blood after VI, there is likely to be a very low viraemia. The presence of CPE in cell cultures inoculated with larval homogenates suggests that the virus in the larvae was infectious, thereby showing high potential for transmission to recipient animals.

Transovarial passage of pathogens does not seem to be a common route for A. hebraeum. Although it is reported that A. hebraeum transmits CCHF (Shepherd et al. 1989, Shepherd et al. 1991), attempts to show transovarial passage of the virus failed and the virus could not be demonstrated in larvae produced by females fed on infected animals (Shepherd et al. 1991). However transovarial transmission by A. hebraeum has been demonstrated for Rickettsia conori (Kelly and Mason 1991) and Ehrlichia (Cowdria) ruminantium (Bezuidenhout and Jacobsz 1986).

Cattle are preferred hosts for both immature and adult $A$. hebraeum ticks and although immature stages (e.g. larvae) attach mostly on the feet, legs and muzzle (Walker 2003), their attachment on the ears in this study was very high. Therefore, the animal host or attachment site does not seem to have adversely affected the transmission of the virus.

Evidence of transovarial passage of LSDV in R. decoloratus in this study, strengthens the report of transovarial transmission of LSDV by Tuppurainen and co-workers (2013b). Since 
R. decoloratus is a one host tick (Walker 2003), transmission of pathogens between hosts is expected to be vertical through transovarial passage. Transstadial passage from larvae to nymphs and adults may occur on the same host and this may explain the more prominent development of LSD reported in recipient animals challenged with $R$. decoloratus (Tuppurainen et al. 2013b) compared to the infection developed by animals challenged with larvae of 3-host ticks (A. hebraeum and $R$. appendiculatus). Rhipicephalus decoloratus has also been shown to transmit Babesia bigemina through vertical transmission (Buscher 1988, Okon et al. 2011). No evidence of transovarial transmission of other viruses by $R$. decoloratus has been reported. An attempt to show transovarial transmission of CCHF by $R$. decoloratus was not successful (Shepherd et al. 1991).

Transovarial passage of LSDV by R. appendiculatus in this study was quite poor. The virus was only detected in the larvae after testing the VI material by real-time PCR, with high $\mathrm{C}_{\mathrm{t}}$ values of 35 - 36. Similarly, transovarial transmission by $R$. appendiculatus infected larvae to recipient animal RR2 was transient. Infection was indicated clinically by fever $\left(39.3^{\circ} \mathrm{C}\right)$ on Day 23 pi. It was confirmed by detection of viraemia by real-time PCR ( $C_{t}$ values of 36.7 and 38.1 on Days 21 and 23, respectively) and detection of LSDV by real-time PCR in VI material on Day 14 dpa as well that of the pooled and concentrated VI supernatants.

This study demonstrates transovarial passage of LSDV by A. hebraeum, R. appendiculatus and $R$. decoloratus ticks. The findings of this study and other published LSDV transmission studies (Tuppurainen et al. 2013a, Tuppurainen et al. 2013b) indicate a high possibility for ticks to be reservoir hosts for LSDV in nature. The overwintering period in the life cycle of some tick species such as $R$. decoloratus ticks (after repletion of adults) (Bryson et al. 2002, Walker 2003), may play a significant role in the overwintering of LSDV. The limitations on the number of test animals used did not allow the use of statistical analysis in this study and 
more comprehensive investigations may be required to fully ascertain transovarial passage of LSDV in ticks in the field settings.

\section{Acknowledgements}

This was a collaborative study between the DVTD, FVS, UP, South Africa and the Pirbright Institute, Pirbright, United Kingdom. The project was funded by the Combating Infectious Diseases of Livestock for International Development (CIDLID) research programme, the Department of International Biotechnology and Biological Sciences Research Council (BBSRC), the UK government, the Department for International Development (DFID) and the Scottish Government (CIDLID project number BB/H009361/1). The authors also thank Ms Karen Ebersohn, Rebone Mahlare and Milana Troskie for their technical assistance and the ARC-OVI for supplying the ticks.

\section{References}

Beard PM, Sugar S, Bazarragchaa E, Gerelmaa U, Tserendorj S, Tuppurainen E, Sodnomdarjaa R (2010) A description of two outbreaks of capripoxvirus disease in Mongolia. Vet Microbiol 142:427-431

Bezuidenhout JD, Jacobsz CJ (1986) Proof of transovarial transmission of Cowdria ruminantium by Amblyomma hebraeum. Onderstepoort J Vet Res 53:31-34

Bowden TR, Babiuk SL, Parkyn GR, Copps JS, Boyle DB (2008) Capripoxvirus tissue tropism and shedding: a quantitative study in experimentally infected sheep and goats. Virology 371:380-393

Bryson NR, Tice GA, Horak IG, Stewart CG, Plessis BJAd (2002) Ixodid ticks on cattle belonging to small-scale farmers at 4 communal grazing areas in South Africa. J S Afr Vet Assoc 73:98-103

Burdin ML (1959) The use of histo-pathological examinations of skin material for the diagnosis of lumpy skin disease in Kenya. Bull Epizoot Dis Afr 7:27-36

Buscher G (1988) The infection of various tick species with Babesia bigemina, its transmission and identification. Parasitol Res 74:324-330 
Chihota CM, Rennie LF, Kitching RP, Mellor PS (2001) Mechanical transmission of lumpy skin disease virus by Aedes aegypti (Diptera: Culicidae). Epidemiol Infect 126:317-321

Coetzer JAW (2004) Lumpy skin disease. In: . Oxford University Press, Oxford, pp 12681276

Danielova V, Holubova J (1991) Transovarial transmission rate of tick-borne encephalitis virus in Ixodes ricinus ticks.

Davies FG (1981) Lumpyskin disease:751-764

Higuchi R, Fockler C, Dollinger G, Watson R (1993) Kinetic PCR analysis: real-time monitoring of DNA amplification reactions. Bio/Technology 11:1026-1030

Kelly PJ, Mason PR (1991) Transmission of a spotted fever group rickettsia by Amblyomma hebraeum (Acari: Ixodidae). J Med Entomol 28:598-600

King A, Lefkowitz E, Adams MJ, Carstens EB (2011) Virus Taxonomy, 1st Edition. Ninth Report of the International Committee on Taxonomy Viruses:1344

Kumar SM (2011) An outbreak of Lumpy Skin Disease in a Holstein dairy herd in Oman: a clinical report. Asian Journal of Animal and Veterinary Advances 6:851-859

Lubinga JC, Tuppurainen ESM, Stoltsz WH, Eberhson K, Coetzer JAW, Venter EH (2013) Detection of lumpy skin disease virus in saliva of ticks fed on blood of infected cattle. Exp Appl Acarol

Okon OE, Opara KN, Etim SE, Arong GA, Oku EE, Iboh CI (2011) Experimental transmission of Babesia bigemina by Boophilus decoloratus in cattle. Research Journal of Parasitology 6:168-175

Shepherd AJ, Swanepoel R, Shepherd SP, Leman PA, Mathee O (1991) Viraemic transmission of Crimean-Congo haemorrhagic fever virus to ticks. Epidemiol Infect 106:373382

Shepherd AJ, Swanepoel R, Cornel AJ, Mathee O (1989) Experimental studies on the replication and transmission of Crimean-Congo Hemorrhagic Fever virus in some African tick species. Am J Trop Med Hyg 40:326-331

Tuppurainen ESM, Lubinga JC, Stoltsz WH, Troskie M, Carpenter ST, Coetzer JAW, Venter EH, Oura CAL (2013a) Mechanical transmission of lumpy skin disease virus by Rhipicephalus appendiculatus male ticks. Epidemiology and infection, Epidemiol Infect 141, 2:425-430

Tuppurainen ESM, Lubinga JC, Stoltzs WH, Troskie M, Carpenter ST, Coetzer JAW, Venter EH, Oura AL (2013b) Evidence of vertical transmission of lumpy skin disease in Rhipicephalus decoloratus ticks. Ticks and tick borne diseases 
Tuppurainen ES, Venter EH, Coetzer JA (2005) The detection of lumpy skin disease virus in samples of experimentally infected cattle using different diagnostic techniques.

Onderstepoort J Vet Res 72:153-164

Tuppurainen ESM, Oura CAL (2012) Review: lumpy skin disease: an emerging threat to Europe, the Middle East and Asia. Transboundary and Emerging Diseases 59:40-48

Tuppurainen ESM, Stoltsz WH, Troskie M, Wallace DB, Oura CAL, Mellor PS, Coetzer JAW, Venter EH (2011) A potential role for ixodid (hard) tick vectors in the transmission of lumpy skin disease virus in cattle. Transboundary and Emerging Diseases 58:93-104

Walker A (2003) Ticks of domestic animals in Africa : a guide to identification of species. Bioscience Reports, Edinburgh

Weiss KE (1968) Lumpy skin disease virus. Virology Monographs 3:111-131

Wilson ML, Gonzalez JP, Cornet JP, Camicas JL (1991) Transmission of Crimean-Congo Haemorrhagic Fever virus from experimentally infected sheep to Hyalomma truncatum ticks. Res Virol 142:395-404

Yeruham I, Nir O, Braverman Y, Davidson M, Grinstein H, Haymovitch M, Zamir O (1995) Spread of lumpy skin disease in Israeli dairy herds. Vet Rec 137:91-93 